\title{
EDITORIAL
}

\section{Cognitive stimulation in ICU patients: should we pay more attention?}

\author{
Marc Turon ${ }^{1,2 *}$, Sol Fernandez-Gonzalo, ${ }^{1,2}$, Victor Gomez-Simon ${ }^{1,3}$, Lluís Blanch¹,34 and Mercè Jodar2,5
}

Advances in ICUs have raised survival rates, but they have highlighted the need to reduce the morbidity of ICU patients and improve their short- and long-term functional outcomes. Frequently these patients, especially with acute respiratory distress syndrome, present neurocognitive impairments [1] that extend beyond their acute phase and hospital stay and lead to significant deficits in quality of life [2,3]. These neurocognitive sequelae generate health and economic problems related to the dependency of survivors. Neurocognitive impairments may be understood as a manifestation of occult brain damage secondary to underlying pathophysiological mechanisms related to critical illness [4]. Therefore, it might be interesting to consider these patients as brain damaged patients and apply therapeutic tools, such as cognitive stimulation, that have proven effective in treating neurocognitive impairments in acquired brain injury patients [5].

A number of considerations must be taken into account with regard to when and how cognitive intervention is applied. After hospital discharge we must consider the rehabilitation or amelioration of cognitive impairments that ICU survivors show in their daily lives. However, cognitive interventions during hospitalization should be focused on nonspecific stimulation of overall cognitive functions, in order to prevent the occurrence of these long-term sequelae or reduce their severity.

Virtual reality (VR) is a useful therapeutic tool that allows patients to experience virtual environments that appear and feel similar to the real world through natural interaction. VR has been applied to acquired brain injury patients using a supermarket environment to treat executive dysfunctions [6] or a virtual office to assess learning and memory [7]. Finally, some studies have explored the possibilities offered by VR in assessing and treating attention deficits [8]. There are no experiences of this

*Correspondence: mturon@tauli.cat

'Research Department, Fundació Parc Taulí University Institute, Universitat Autònoma de Barcelona. Parc Taulí University Hospital. 08208 Sabadell, Spain Full list of author information is available at the end of the article type in the ICU, except for the use of interactive video games in early physical rehabilitation [9].

Critically ill patients are in a state of sensory deprivation during their ICU stay and VR can physically and cognitively stimulate the patient in a safe and controlled environment. The use it or lose it principle posits that neuronal activation can enhance cognitive function and results in improved neuronal survival in acquired brain injury [10]. In the ICU context, this concept suggests that cognitive stimulation, as similar to the patient's daily life as possible, can have a beneficial effect on cognitive function, preventing the emergence of neurocognitive impairments or improving cognitive and functional outcomes after discharge. It is time to consider cognitive stimulation as a challenging future intervention for critically ill patients.

Abbreviations
VR, virtual reality.

\section{Competing interests}

MT, SFG, VGS and LB are investigators of the project Early neurocognitive rehabilitation in critically ill patients with acute acquired brain injury funded by La Fundació Marató TV3 2010. LB has developed patented inventions related to monitoring ventilator signals. The license for these patents belongs to Corporació Sanitària Parc Taulí (Spain). LB owns 10\% of BetterCare SL, a research and development spin-off of Corporació Sanitària Parc Taulí (Spain). MJ declares that she has no competing interests.

\section{Author details}

'Research Department, Fundació Parc Taulí University Institute, Universitat Autònoma de Barcelona. Parc Taulí University Hospital. 08208 Sabadell, Spain. ${ }^{2}$ Psychopathology and Neuropsychology Research Unit, Department of Clinical and Health Psychology, Universitat Autònoma de Barcelona, International Excellence Campus. 08193 Bellaterra, Spain. ${ }^{3}$ Critical Care Department, Parc Taulí University Hospital, Universitat Autònoma de Barcelona, International Excellence Campus. 08193 Bellaterra, Spain. ${ }^{4} \mathrm{CIBER}$ Enfermedades Respiratorias, Instituto de Salud Carlos III. Madrid, Spain. ${ }^{5}$ Neurology Department, Parc Taulí University Hospital, Universitat Autònoma de Barcelona, International Excellence Campus. 08193 Bellaterra, Spain.

Published: 20 June 2013

\section{References}

1. Hopkins RO, Jackson JC: Short- and long-term cognitive outcomes in intensive care unit survivors. Clin Chest Med 2009, 30:143-153.

2. Hopkins RO, Weaver LK, Collingridge D, Parkinson RB, Chan KJ, Orme JF Jr: Two-year cognitive, emotional, and quality-of-life outcomes in acute respiratory distress syndrome. Am J Respir Crit Care Med 2005, 171:340-347.

3. Herridge MS, Tansey CM, Matté A, Tomlinson G, Diaz-Granados N, Cooper A, Guest CB, Mazer CD, Mehta S, Stewart TE, Kudlow P, Cook D, Slutsky AS, Cheung AM: Functional disability 5 years after acute respiratory distress 
syndrome. N Eng J Med 2011, 364:1293-1304.

4. Pustavoitau A, Stevens RD: Mechanisms of neurologic failure in critical illness. Crit Care Clin 2008, 24:1-24.

5. Cicerone KD, Langenbahn DM, Braden C, Malec JF, Kalmar K, Fraas M, Felicetti T, Laatsch L, Harley JP, Bergquist T, Azulay J, Cantor J, Ashman T: Evidencebased cognitive rehabilitation: updated review of the literature from 2003 through 2008. Arch Phys Med Rehabil 2011, 92:519-530.

6. Gunther ML, Jackson JC, Ely EW: The cognitive consequences of critical illness: practical recommendations for screening and assessment. Crit Care Clin 2007, 23:491-506.

7. Girard TD, Jackson JC, Pandharipande PP, Pun BT, Thompson JL, Shintani AK, Gordon SM, Canonico AE, Dittus RS, Bernard GR, Ely EW: Delirium as a predictor of long-term cognitive impairment in survivors of critical illness. Crit Care Med 2010, 38:1513-1520.
8. Hopkins RO, Jackson JC: Short- and long-term cognitive outcomes in intensive care unit survivors. Clin Chest Med 2009, 30:143-153.

9. Kho ME, Damluji AA, Zanni JM, Needham DM: Feasibility and observed safety of interactive video games for physical rehabilitation in intensive care unit: a case series. J Crit Care 2012, 27:219.e1-e6.

10. Shors TJ, Anderson ML, Curlik DM Jr, Nokia MS: Use it or lose it: how neurogenesis keeps the brain fit for learning. Behav Brain Res 2012, 227:450-458

doi:10.1186/cc12719

Cite this article as: Turon M, et al: Cognitive stimulation in ICU patients: should we pay more attention? Critical Care 2013, 17:158. 